\title{
Personality Profile of School Students
}

\author{
Veena Chakravarthy ${ }^{1}$, Dr. V. Chandramohan ${ }^{2}$
}

\section{ABSTRACT:}

Personality refers to distinctive patterns of behaviour that characterizes each individual's adaptation to the situations in life. Personality is defined as an enduring pattern of psychological and behavioural characteristics by which each person can be compared and contrasted with each other. Academic success depends on the best use of personality dimensions. Students encounter many hurdles in achieving academic success. Many of these hurdles are within their personality traits. Academic success depends on the best use of personality dimensions. What qualities make students more successful in their life as well as their workplace is a fascinating question? The aim of the present study is to assess the personality traits of the school students and draw a typical personality profile of high school students. Three hundred healthy and well motivated school students, 150 boys and 150 girls, studying Higher Secondary Course at Saru Matriculation Higher Secondary School, Satyamangalam, Erode District, constitute as a sample for the present study. School students are administered with 16 Personality Factor Questionnaire (16 PF), for the purpose of finding out basic personality traits. A typical personality profile of school student. is drawn. Gender differences, between Boys and Girls, on personality traits are highlighted. Implications of the findings are discussed.

Keywords: Typical Personality Profile Of School Students, Gender Difference

The term "Personality" has been derived from a Latin word, "Persona", which means mask. Personality" refers to distinctive patterns of behaviour that characterizes each individual's adaptation to the situations in life. Personality is defined as an enduring pattern of psychological and behavioural characteristics by which each person can be compared and contrasted with each other. Personality is more or less stable and enduring organization of a person's character (conative), temperament (affective), intellect (cognitive) and physique (neuroendocrine endowment). Personality is made up of characteristic patterns of thought, feelings and behavior that make a person unique. Personality arises from within the individual and remains fairly consistent throughout the life. Academic success depends on the best use of personality dimensions. Students encounter many hurdles in achieving academic success. Many of these hurdles are within their personality traits.

${ }^{1}$ Research Scholar, Department: Psychology, Bharathiar University, Coimbatore

${ }^{2}$ Research Supervisor, Reader in Psychology, Institute of Aerospace Medicine, IAF, Vimanapura (PO), Bangalore

(C) 2015 I V Chakravarthy, V Chandramohan; licensee IJIP. This is an Open Access Research distributed under the terms of the Creative Commons Attribution License (http://creativecommons.org/licenses/by/2.0), which permits unrestricted use, distribution, and reproduction in any Medium, provided the original work is properly cited. 


\section{Personality Profile of School Students}

The studies based on 16 personality factor test revealed that administrative trainees undergoing training at Air Force Academy, Hyderabad, were more stable in their emotions, happy go lucky type, humble and accommodating, practical oriented, less apprehensive, more conservative, low in anxiety and extroverts than the Air Traffic Control Officer (ATCO) trainees. On the other hand, the ATCO were more intelligent than the admin trainees (Chandramohan et al., 1997, 1998).

Abu Bakkar Sithikh (2014) carried out a study on high school students and found that personality traits have a positive relationship with absenteeism. The students, who were high on neuroticism, were not regular to the school.

Personality differs according to occupations. Every job needs to have a given temperament and one should select their jobs based on these temperaments. What qualities make students more successful in their life as well as their workplace is a fascinating question? Researchers have tried to find out a satisfactory answer. The present study is an attempt in this direction.

\section{AIM}

The aim of the present study is to assess the personality traits and draw a typical personality profile of the high school students

\section{OBJECTIVE}

Objectives of the present study are

1) To delineate the personality profile of a typical high school student

2) To compare the personality profile of boys and girls

3) To find out, if there exists, any gender differences, on personality traits

\section{MATERIALS AND METHOD}

Three hundred healthy and well motivated school students, 150 boys and 150 girls, age ranging from 15 to 18 years, studying Higher Secondary Course at Saru Matriculation Higher Secondary School, Satyamangalam, Erode District, constitute as a sample for the present study. School students are assessed on $\mathbf{1 6} \mathbf{P F}$, an objective personality test, for the purpose of drawing a typical personality profile of school students. Short detail of Psychological tests is given below:

16 PERSONALITY FACTOR QUESTIONNAIRE - FORM “D” (16 PF) - Cattell (1963, Cattell et al., 1970) has developed 16 PF to assess basic personality structure of an individual. $16 \mathbf{P F}$ is a well known objectively score able factorial test of personality. $\mathbf{1 6}$ PF is multi dimensional set of sixteen questionnaire scale arranged in an omnibus form. It is comprehensive in coverage and give information regarding an individual's standing on sixteen Primary Factors and eight Second Order Factors. Cattell has developed different forms of 16 PF and they are Form 'A', 'B', 'C', 'D' and 'E'. The Computerised version of $\mathbf{1 6} \mathbf{P F}$ has been developed by Chandramohan (1991), at Institute of Aerospace Medicine, IAF, Bangalore, is 


\section{Personality Profile of School Students}

used for analysing the responses. On obtaining the STEN score, an individual's relating standing in each of the factor is expressed on a Profile Chart. The STEN score positions for each factor are distributed over ten equal interval STEN points (Standard Score Points) from1 through 10, with the population average fixed at 5.5 and standard deviation at1. 16 PF test Form "D" is used in the present study. This test has got 105 statements. There is no right or wrong answers. Answer as honestly as possible to give the first response coming into your mind. Three boxes are given on the answer sheet to record the responses. Students are asked to choose one answer out of 3 choices, by putting, a " $\sqrt{ }$ " mark inside the box. Here, A - True or Yes, B Sometimes, In between, Occasionally, Uncertain, C - False or No. Try to avoid choosing 'B' as an answer because it does not reflect any qualities. It usually takes 30 minutes to complete.

Scoring: Each answer is awarded with marks 0,1 and 2. Whereas, for Factor B, the scores are 0 (incorrect) or 1 (Correct). The total score constitute the raw score for that particular trait. The raw score is further converted into Standard (STEN) score, using norms supplied by the author. The STEN scores are reflected on the Profile Chart to see the individual's relative standing on the 16 Primary Traits. The Second Order Factors are calculated from the scores of Primary Factors. The $\mathbf{8}$ Second Order factors are, as follows:

$\begin{array}{llll}\text { Factor I } & - & \text { ANXIETY } & \text { - Low Vs High Anxiety } \\ \text { Factor II } & - & \text { EXTRAVERSION } & \text { - Introversion Vs Extraversion } \\ \text { Factor III } & - & \text { TOUGH POISE } & \text { - Emotional Sensitivity Vs Alert poise } \\ \text { Factor IV } & - & \text { INDEPENDENCE } & \text { - Subduedness Vs Independence } \\ \text { Factor V } & - & \text { SUPEREGO/CONTROL } & \text { - Low Control Vs High Control } \\ \text { Factor VI } & - & \text { ADJUSTMENT } & \text { - Neuroticism Vs Adjustment } \\ \text { Factor VII } & - & \text { LEADERSHIP } & \text { - Low Leadership Vs High Leadership } \\ \text { Factor VIII } & - & \text { CREATIVITY } & \text { - Low Creativity Vs High Creativity } \\ \text { Md (Motivational distortion score) - STEN score above 7, the test is invalid }\end{array}$

Significance level of STEN score on Primary Factors

$\begin{array}{lll}\text { STEN 1-3 } & = & \text { Low score } \\ \text { STEN } 4-6= & \text { Average } \\ \text { STEN 8-10 } & = & \text { High score }\end{array}$

Significance level of STEN score on Second Order Factors

STEN $1-4=$ Low score

STEN $5-6=$ Average

STEN $7-10=$ High score

STEN score 4 and 7 shows tendency towards that particular trait Scoring: Standard scoring procedure adopted. 
Personality profile of Boys are compared with the Girls. to find out gender difference, if any, existing on personality traits.

Student " $\mathrm{t}$ " test is employed for analyzing the data.

\section{FINDINGS AND DISCUSSION}

The findings of the present study are discussed on Tables 1 and 2 Figures 1 and 2.

Table 1 and Figure 1 show that School students are ambivert, socially bold, rule-bound, conservative, adequate on emotional stability, having control over feelings and behavior and free from tension.

On Second order factors (SOF), students are low on emotional sensitivity and creativity. Results clearly indicate that students are sensitive to their feelings as well as feelings of others. If they have difficulties, they are likely to involve in rapid thought with insufficient action, follow triedand-true way of doing things rather than trying new ones do not spend much time in generating ideas but want workable and practical solutions.

Table 1: Mean STEN of the School Students $(n=300)$ on 16 PF

\begin{tabular}{|c|c|c|}
\hline PERSONALITY FACTORS & MEAN & SD \\
\hline Md & 4.87 & 2 \\
\hline $\mathbf{A}$ & 6.63 & 2 \\
\hline B & 5.78 & 2 \\
\hline $\mathbf{C}$ & 5 & 1 \\
\hline $\mathbf{E}$ & 5.11 & 2 \\
\hline $\mathbf{F}$ & 6.23 & 2 \\
\hline G & 6.01 & 2 \\
\hline $\mathbf{H}$ & 6.67 & 3 \\
\hline I & 5.68 & 1 \\
\hline $\mathbf{L}$ & 4,52 & 2 \\
\hline $\mathbf{M}$ & 4.71 & 2 \\
\hline $\mathbf{N}$ & 4.65 & 2 \\
\hline $\mathbf{O}$ & 5.06 & 1 \\
\hline Q1 & 5.41 & 2 \\
\hline Q2 & 4.87 & 2 \\
\hline Q3 & 6.56 & 2 \\
\hline Q4 & 4.98 & 1 \\
\hline \multicolumn{3}{|l|}{ SOF } \\
\hline $\mathbf{I}$ & 4.59 & 1 \\
\hline II & 5.42 & 1 \\
\hline III & 4.11 & 1 \\
\hline IV & 5.44 & 2 \\
\hline $\mathbf{V}$ & 5.8 & 2 \\
\hline VI & 6.24 & 1 \\
\hline VII & 5.9 & 1 \\
\hline VIII & 3.86 & 1 \\
\hline
\end{tabular}




\section{Personality Profile of School Students}

Table 2 and Figure 2 show that Boys are pronounced extroverts, good natured, easy going, emotionally expressive, soft hearted, cooperative, attentive to people and are kind individuals. Socially bold, rule-bound, happy-go-lucky type, practical oriented, conservative, high on selfconfidence and emotional stability, having good control over feelings and behavior and remain calm, cool and relaxed. Due to this high stress tolerance they are able to adjust to the situations where sudden adjustments are needed and free from tension.

On SOF, students are high on extroversion, independence, super ego control, adjustment and leadership but low on anxiety. Results clearly indicate that students are a typical extrovert, happy-go-lucky type, independent-minded and self assured, having strong super ego control and conform to the expectations of others, quiet reliable and well adjusted, high on self confidence, adaptability, flexibility stable emotionally and high on stress tolerance and relaxed, born leaders and sociable, 


\section{Personality Profile of School Students}

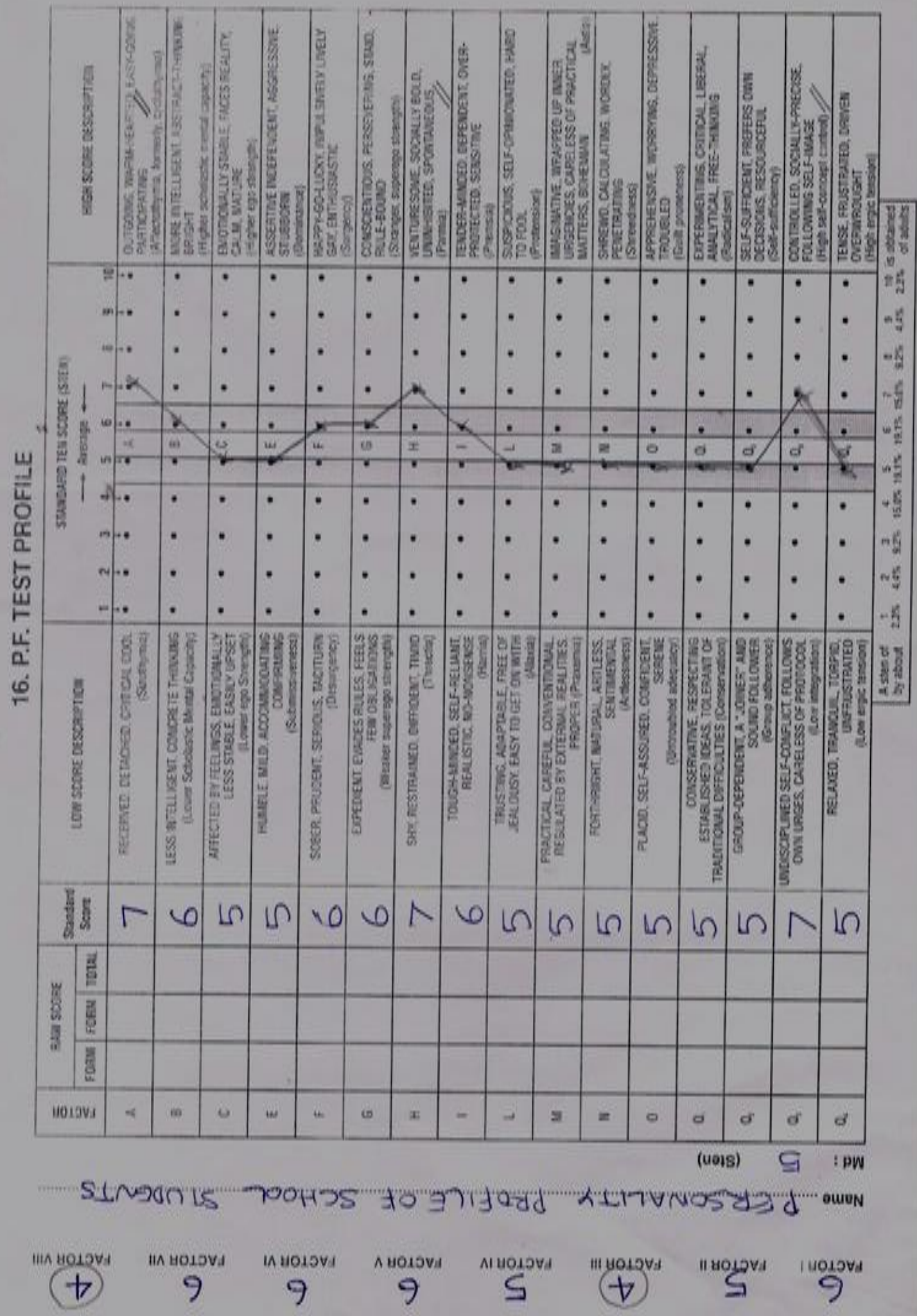




\section{Personality Profile of School Students}

On the other hand, Girls are pronounced extrovert, good natured, easy going, emotionally expressive, soft hearted, cooperative, attentive to people and are kind individuals, socially bold, happy-go-lucky type, rule-bound, forthright, high on self confidence and emotional stability, having good control over feelings and behavior and remain relaxed. Due to this high stress tolerance they are able to adjust to the situations where sudden adjustment is needed and free from tension.

On SOF, they are high on extroversion, independence, super ego control, adjustment and leadership but low on anxiety. Results clearly indicate that they are a typical extrovert and happy-go-lucky type, independent-minded and self assured, having strong super ego control and conform to the expectations of others, quiet reliable and well adjusted, high on self confidence, stable emotionally and high on stress tolerance, adaptable, flexible and relaxed, born leaders and sociable.

\section{Comparison of Mean STENS of Boys vs. Girls}

Table 2 and Figure 2 show the comparison of personality traits of Boys and Girls. Boys significantly differ (P. 0001) in the personality traits of Girls. Boys are higher (P. 0001) on the personality traits of forthright, self--confidence and controlling feelings and emotions than the Girls.

On the other hand, Girls are higher (P. 0001) on intelligence, emotional stability and independence than the Boys.

\section{SUMMARY AND CONCLUSIONS}

The following conclusions are drawn from the present study:

1. School students are ambivert, socially bold, rule-bound, conservative, adequate on emotional stability, having control over feelings and behavior and free from tension, sensitive to their feelings as well as feelings of others. follow tried-and-true way of doing things rather than trying new ones

2. Boys are forthright, self--confident and controlling feelings and emotions easily

3. Girls are more intelligent, high on emotional stability and independent-minded 


\section{Personality Profile of School Students}

Table 2 : Mean STENS of Boys Vs. Girls

\begin{tabular}{|c|c|c|c|c|c|c|}
\hline \multirow{2}{*}{$\begin{array}{c}\text { PERSONALITY } \\
\text { FACTORS }\end{array}$} & \multicolumn{2}{|c|}{$\begin{array}{c}\text { BOYS } \\
(\mathbf{n}=\mathbf{1 5 0})\end{array}$} & \multicolumn{2}{c|}{$\begin{array}{c}\text { GIRLS } \\
(\mathbf{n = 1 5 0})\end{array}$} & \multirow{2}{*}{ 't' - } & P - \\
\cline { 2 - 5 } & MEAN & SD & MEAN & SD & VALUE & VALUE \\
\hline Md & 4.92 & 1 & 4.88 & 2 & 0.13 & NS \\
\hline A & 8.44 & 1 & 7.92 & 1 & 2.60 & 0.01 \\
\hline B & 4.76 & 1 & 7.96 & 1 & 16.00 & 0.0001 \\
\hline C & 6.64 & 1 & 8.28 & 1 & 6.20 & 0.0001 \\
\hline E & 4.92 & 1 & 5.12 & 2 & 0.63 & NS \\
\hline F & 8.04 & 2 & 8.04 & 1 & 0 & NS \\
\hline G & 8.16 & 1 & 8.04 & 1 & 0.38 & NS \\
\hline H & 7.84 & 1 & 8 & 1 & 0.80 & NS \\
\hline I & 5.92 & 1 & 5.2 & 2 & 6.84 & 0.01 \\
\hline L & 4.96 & 2 & 4.68 & 2 & 0.95 & NS \\
\hline M & 4.4 & 2 & 3.68 & 2 & 1.80 & NS \\
\hline N & 4.4 & 2 & 3.36 & 2 & 2.60 & 0.01 \\
\hline O & 3.84 & 2 & 4.8 & 2 & 2.40 & 0.01 \\
\hline Q1 & 3.6 & 2 & 4.52 & 2 & 2.30 & 0.02 \\
\hline Q2 & 3.96 & 2 & 8 & 1 & 12.78 & 0.0001 \\
\hline Q3 & 8.08 & 2 & 3.08 & 1 & 15.81 & 0.0001 \\
\hline Q4 & 3.56 & 1 & 3.6 & 2 & 0.20 & NS \\
\hline SOF & & & & & & \\
\hline I & 3.84 & 2 & 3.6 & 2 & 0.60 & NS \\
\hline II & 7.92 & 2 & 7.92 & 1 & 0 & NS \\
\hline III & 4.6 & 1 & 5.8 & 2 & 3.0 & 0.001 \\
\hline IV & 7.8 & 2 & 8 & 1 & 0.63 & NS \\
\hline V & 8.08 & 1 & 8 & 1 & 0.25 & NS \\
\hline VI & 8.16 & 1 & 8.04 & 1 & 0.38 & NS \\
\hline VII & 8 & 1 & 7.96 & 1 & 0.13 & NS \\
\hline VIII & 4.6 & 1 & 5.44 & 1 & 2.66 & 0.01 \\
\hline & & & & & & \\
\hline
\end{tabular}




\section{Personality Profile of School Students}

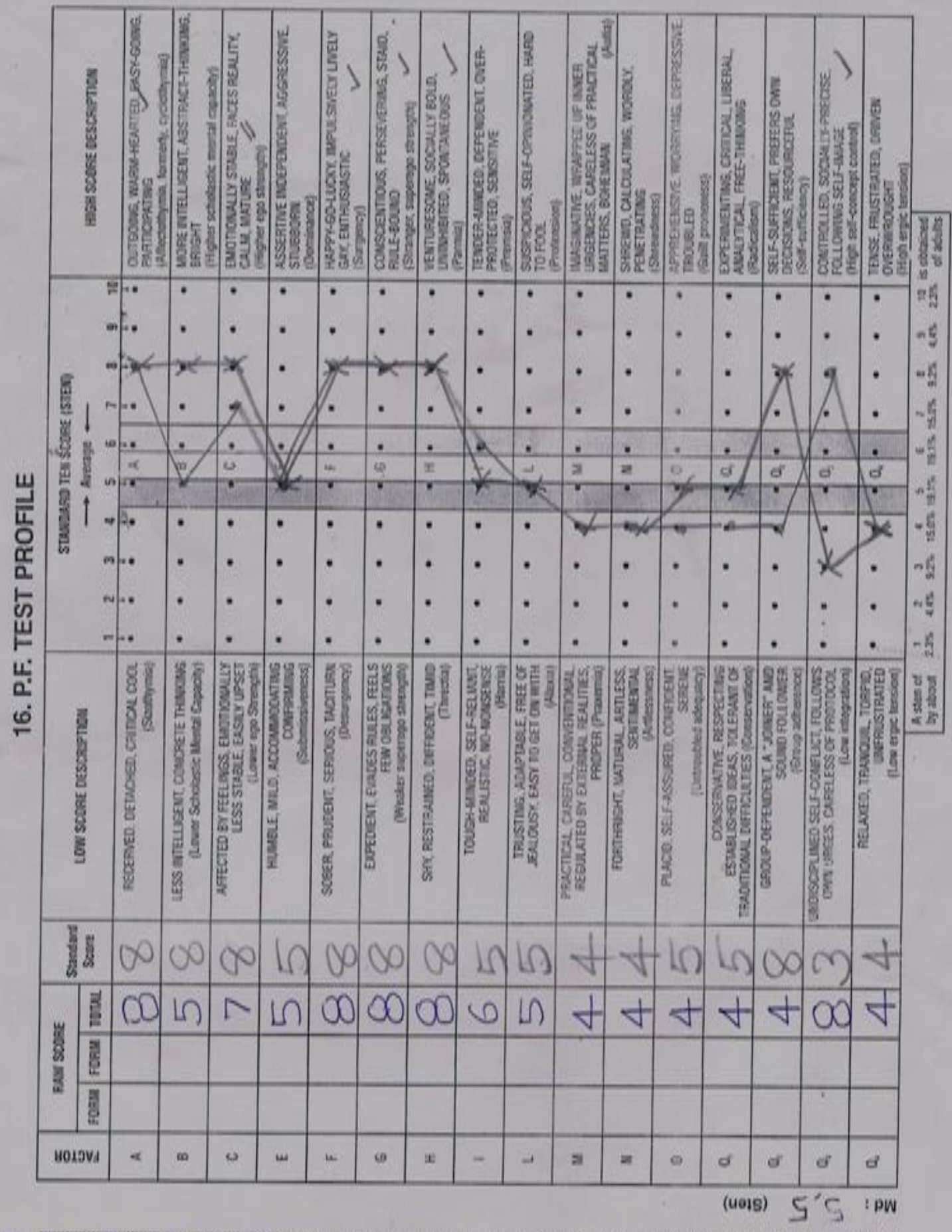

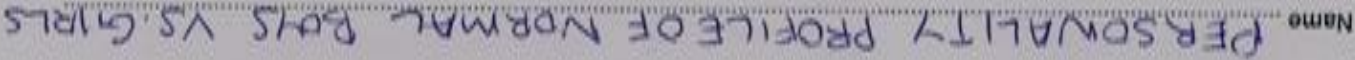

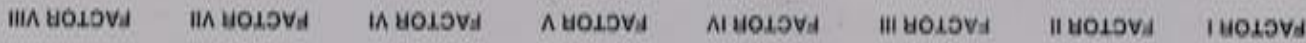




\section{REFERENCES}

Abubakkar Sithikh (2014). Personality trait associated with frequent Absenteeism. Proceedings of the UGC Sponsored National Conference on Enhancing Psychological Wellbeing, Organised by the Depatment of Psychology, Bharathiar University, Coimbatore, 20$21 \mathrm{Feb}$.

Cattell, RB., Eber, HW (1962). Manuals for Forms C and D 16 Personality questionnaire. "The 16 PF". Young adults and adults. USA: Institute of Personality and Ability Testing

Cattell, RB., Herbert, WE., Tatsuoka, MM (1970). Handbook for the Sixteen Personality Factor Questionnaire (16 PF): Individual, Educational, Industrial and Research Psychology for use with all Forms of the test. Illinois : Institute of Personality and Ability Testing

Chandramohan, V., Air Cmde Sengupta, AK., Sunilkumar, Kandhasamy, KS (1997). Personality profile of Air Traffic Controller. J. of Aerospace Medicine. 1997; 41 (2): pp. 53-60

Chandramohan, V (1998). Application of Behaviour therapy and Ground simulator in the Management of Airsickness. Ph.D., Thesis. Bangalore University.

Chandramohan (1991). Computerization of 16 Personality Factor Test. IAM/Project No. 139/ $1 / 89$. 